Mens

revue d'histoire intellectuelle de l'Amérique française

\title{
L’histoire sociale des idées comme histoire intellectuelle
}

\section{Yvan Lamonde}

Volume 1, numéro 2, printemps 2001

URI : https://id.erudit.org/iderudit/1024444ar

DOI : https://doi.org/10.7202/1024444ar

Aller au sommaire du numéro

Éditeur(s)

Centre de recherche en civilisation canadienne-française

ISSN

1492-8647 (imprimé)

1927-9299 (numérique)

Découvrir la revue

Citer cet article

Lamonde, Y. (2001). L'histoire sociale des idées comme histoire intellectuelle. Mens, 1(2), 87-96. https://doi.org/10.7202/1024444ar d'utilisation que vous pouvez consulter en ligne.

https://apropos.erudit.org/fr/usagers/politique-dutilisation/ 


\title{
L'HISTOIRE SOCIALE DES IDÉES COMME HISTOIRE INTELLECTUELLE
}

\author{
YVAN LAMONDE \\ Département de langue et littérature françaises \\ Université McGill
}

Plus de trente ans de pratique de l'histoire intellectuelle me font voir la richesse de la définition de la méthode proposée par le linguiste et ethnologue Georges Dumézil. La méthode, écrivait-il, c'est le chemin une fois parcouru'. Il en va ainsi pour ma définition ou ma caractérisation de l'histoire intellectuelle et je vais donc retenir du chemin parcouru trois balises : les effets du point de départ, le caractère dialectique de cette définition et les marques de l'historiographie depuis les années 1950.

De ce que je peux voir de cet itinéraire, il me semble que la détermination primordiale demeure la conscience claire que j'avais au milieu de la décennie 1960 de ma volonté de faire un jour une synthèse de l'histoire intellectuelle du Québec. Ce choix a balisé tout le chemin et il me semble faire la différence entre une conception plus ponctuelle, plus monographique de l'histoire intellectuelle et une conception plus englobante dans ses objets et sa temporalité.

\section{Les effets du point de départ}

Au point de départ, mes études en Philosophie à l'Université de Montréal m'ont initié à l'analyse interne des idées, à l'étude de la cohérence systémique de grandes idées, de l'empirisme à l'idéalisme en passant par le cogito cartésien. Mais d'analyse externe, de contextualisation, d'historicité, point. Si cet entrainement à l'analyse interne des concepts fut un indubitable acquis, ce fut aussi pour moi une invitation à quitter la philosophie non sans avoir forcé le milieu en faisant mon mémoire de maîtrise en 1967 sur La notion de Lebenswelt chez Jobn Wild. Introduction à la pensée de Jobn Wild et à la phénoménologie aux États-Unis?. Le sujet impliquait déjà un choix, celui de m'intéresser, à l'instigation du professeur Roland Houde, à la philosophie américaine contemporaine. Le choix peu orthodoxe de penser qu'on avait pu philosopher et qu'on philosophait à l'extérieur de l'Europe étonna. Il y eut là, pour moi, une 
intuition fondatrice qui se consolida par la lecture de l'ouvrage d'Herbert W. Schneider sur L'bistoire de la philosophie américaine ${ }^{3}$. Schneider me fit comprendre qu'une philosophie en milieu colonial, marquée par des phénomènes comme l'immigration, la circulation des biens, des hommes et des idées, l'importation culturelle et intellectuelle, était non seulement possible mais qu'elle pouvait trouver une voie inédite et valable.

À l'automne 1967, j'étais inscrit à l'Université Laval en Histoire.

\section{Une définition construite de façon dialectique}

Rétrospectivement, je ne peux pas ne pas voir que théorie et pratique se sont mutuellement déterminées. J'étais en mouvement et tel un conducteur, j'avançais en regardant d'abord devant et secondairement dans le rétroviseur. Le rétroviseur me renvoyait à ceux qui, prédécesseurs ou contemporains, avaient écrit ou écrivaient sur l'histoire intellectuelle et avaient pratiqué ou pratiquaient à leur façon la discipline. Parmi les auteurs français, je pense à Daniel Mornet, à Lucien Febvre, à Alphonse Dupront, à Georges Duby, à Robert Mandrou, à Roger Chartier. Chez les Américains, ArthurO. Lovejoy, John Higham, Robert Skotheim, Neil Harris, Thomas Bender, Russel B. Nye, David Hollinger, Robert Darnton. Parmiles historiens canadiens de langue anglaise, D.C. Harvey, Carl Berger, Brian McKillop, Doug Owram et ceux que j'avais invités à participer au numéro thématique du Journal of Canadian Studies / Revue d'études canadiennes surl'histoire culturelle et intellectuelle au Canada (1989).

En même temps que je pouvais confronter entre elles les approches et les définitions et observer comment chacun, en fonction de son domaine de recherche, construisait son objet, j'avançais, je rédigeais mon mémoire de maîtrise surl'enseignement de la philosophie au Collège de Montréal (1790-1876) et ma thèse de doctorat sur la philosophie et son enseignement au Canada français de 1665 à 1920. Sachant depuis mon entrée au Département d'Histoire de Laval que je visais une histoire des idées au Québec, je concevais mes recherches de mémoire et de thèse comme une occasion de balayer large du point de vue des objets à considérer et des sources à retenir éventuellement. 


\section{Les marques de l'historiographie}

L'historiographie québécoise était alors logée à l'enseigne de la primauté de l'histoire économique et sociale, personnifiée à Laval par Fernand Ouellet (qui venait de quitter pour Ottawa), Jean Hamelin et Yves Roby. Il me semble qu'on vivait alors avec une définition de l'histoire sociale à la croisée des groupes sociaux, des classes sociales, de la structure des occupations et des ouvriers syndicalisés. À Laval, l'histoire politique était faite par un juriste bibliothécaire constitutionnaliste érudit, Jean-Charles Bonenfant, relayé par Marc La Terreur, décédé accidentellement dans la fleur de l'âge. Cette histoire politique s'intéressait aux partis, aux constitutions, aux grands hommes et aux crises, mais peu aux idées ou aux courants d'idées qui traversaient la vie canadienne et québécoise. Comment voulait-on, pouvait-on faire de l'histoire culturelle et intellectuelle dans ce contexte?

À l'enseigne des Annales, de Labrousse en particulier, et d'un marxisme diffus, l'histoire économique de Fernand Ouellet et de Jean Hamelin n'était pas très explicite sur les fameux «trois niveaux» (économies, sociétés, civilisations) et leur arrimage, mais on retenait que l'économique était une détermination de première instance mais non déterministe.

Laval était alors l'université où l'on pratiquait le plus l'histoire culturelle. Philippe Sylvain et Pierre Savard étaient familiers avec des historiens de la religion (Latreille, Poulat) et Claude Galarneau avait côtoyé à Paris les représentants du courant «mentalités» de l'École des Annales, Dupront et Mandrou en particulier. Claude Galarneau parlait volontiers de «mentalités» et «d'outillage mentab» (d'où son intérêt pour le collège classique et l'imprimé), mais son propos récurrent était celui de la psychologie collective développée par Maurice Halbwachs, mort à la guerre de 1939-45. À vrai dire, celui qui utilisait le plus la notion de «mentalités» était Fernand Ouellet, familier aussi de Mandrou, qui préfaça son Histoire économique et sociale du Québec de 1760 à $1850^{4}$. Chez Ouellet, le terme «mentalités» réfère à la différence des valeurs entre l'aristocratie coloniale française et la bourgeoisie émergente, à la «mentalité» paysanne confrontée à «l'outillage intellectueb» proposé par le collège-séminaire, à la «psychologie collective» et surtout à cette constellation faite de peur, d'appréhension, de périls et de conspiration, "d'accumulation de rancœun» et d'agressivité du Canadien français installé dans «la permanence» et concevant le capitaliste anglais comme un adversaire (voir l'index de l'ouvrage). 
Très tôt j'ai lu Ouellet et je me rends compte que si j'ai pu commencer à donner une dimension sociale à l'histoire culturelle que j'ambitionnais de faire, c'est à sa mise en place de la bourgeoisie marchande et des professions libérales que je le dois. De même, rétrospectivement, même si on peut différer d'analyse avec lui sur les Rébellions de 1837 et de 1838, il n'en demeure pas moins que sa conjugaison de l'économie, du social et des umentalités» dans les Rébellions constitue l'un des très rares efforts dans l'historiographie québécoise pour donner un sens à cette histoire totale des «trois niveaux" caractéristique de l'École des Annales. Mais dès le colloque de 1975 sur l'histoire socioculturelle organisé par Fernand Ouellet et Robert Mandrou, qui enseignait régulièrement à Laval, je doutais du caractère opératoire de la notion de mentalités ${ }^{5}$. La notion m'apparaissait floue, ambiguë, significativement utilisée par des médiévistes, par des historiens européens travaillant sur des longues durées, moins évidentes dans les sociétés de peuplement des Amériques ${ }^{6}$.

Si la notion de «mentalités» attirait peu finalement, l'esprit des Annales trouva une application évidente dans le rapprochement de l'histoire et des sciences sociales. En histoire culturelle et intellectuelle, cette pollinisation scientifique prit la forme à Laval, avec Fernand Dumont et Jean Hamelin, d'un intérêt pour l'analyse et l'histoire des idéologies. Nous travaillions sur «les projets de société» de la bourgeoisie et de l'Église catholique canadiennes-françaises à partir d'une "grille» thématique dont chacun reconnaissait les limites. Cette approche eut le double avantage de donner un nouveau tour sociologique, un nouvel impératif social à la conception que l'on pouvait se faire de l'histoire culturelle et intellectuelle et de bien faire voir que nous faisions l'histoire d'un groupe social, celui des «définisseurs» de situations.

Après la reconnaissance du travail de Fernand Ouellet de mise en place de la bourgeoisie dans la trame du XIX' siècle et le rappel de l'identité sociale des énonciateurs des idéologies, une troisième conviction sociale s'ajoutait à qui faisait alors de l'histoire culturelle et intellectuelle et elle venait à la fois du marxisme et des recherches historiques sur le mouvement ouvrier et sur le syndicalisme. On ne pouvait pas ne pas être conscient des groupes sociaux ou des classes sociales sur lesquels portaient ses propres travaux. Le thème du "monde ordinaire» était une chose - il rappelait que l'histoire de la culture populaire rurale ET urbaine n'était faite ni par les historiens ni par les ethnologues qui se présentaient surtout comme des 
folkloristes - mais l'histoire sociale m'amena à bien voir que je ne faisais pas l'histoire de toutes et tous, et qu'il fallait préciser de qui je pensais faire l'histoire. Au terme d'un survol historiographique de ce qu'étaient alors les connaissances sur la culture ouvrière à Montréal essentiellement et au moment où je faisais à McGill des cours sur la culture de masse (presse, radio, télévision), je retins pour mon propos deux choses : que la voix du mouvement ouvrier devait être prise en compte à propos de l'instruction publique ou du temps de loisir, par exemple, et qu'il fallait porter attention aux attitudes des élites à l'égard des moyens et phénomènes de masse que j'allais rencontrer au passage du $\mathrm{XIX}^{\mathrm{c}}$ au $\mathrm{XX}^{\mathrm{c}}$ siècle.

\section{Trouver sa voix}

J'avais choisi le Département d'Histoire de l'Université Laval en sachant que l'histoire culturelle était l'un de ses domaines d'excellence. Mais il fallait aussi me familiariser avec les travaux des historiens de Montréal et d'Ottawa, tout en visant, au delà de l'histoire de l'enseignement de la philosophie, à ouvrir de nouvelles pistes, de nouveaux territoires. Je devais donc concevoir ma synthèse éventuelle en partant des «objets» culturels étudiés par les Galarneau, Sylvain, Savard, Wallot, Hare et bientôt Bernard et Eid. A posteriori, on discerne clairement que Galarneau, Sylvain, Savard et en partie Wallot et Hare travaillaient sur les rapports culturels et intellectuels entre le Canada français/Québec, d'une part, et la France et l'Italie, d'autre part, rapports culturels qui incluaient tout autant les hommes, les biens que les courants d'idées (libéralisme, ultramontanisme). L'essentiel des travaux portant sur la culture de et dans la colonie concernait l'imprimé : Wallot et Hare en faisaient l'inventaire jusqu'en 1812, Galarneau scrutait la librairie et les bibliothèques à Québec tout en étudiant les collèges classiques avec ses étudiants. Pour sa part, Sylvain avait commencé à localiser le libéralisme doctrinal dans l'Institut canadien de Montréal, à peu près au même moment où Jean-Paul Bernard s'y intéressait aussi. Tels étaient les «objets» culturels alors étudiés. Le défi était double : prétendre à une identification de tous les objets que devait inclure une histoire culturelle et intellectuelle et, surtout, les intégrer dans un temps biséculaire (1760-1960) et dans un récit cohérent et attrayant. La première bibliographie que je publiai en 1989 sur L'bistoire des idées au Québec ${ }^{\top}$ me servit, par la classification qu'elle requérait, à un premier repérage et à une première organisation chronologique et thématique des «objets» culturels d'une telle histoire. 
Aller à Laval était une bonne façon de trouver sa voix. Aller à Princeton en était une autre, tout aussi bonne qu'aller à Paris. Y compris pour bouquiner et pour voir et comprendre comment les Américains avaient fait et faisaient leur histoire culturelle et intellectuelle, eux qui étaient tôt sortis de la dépendance coloniale et qui pouvaient montrer ce qu'ils avaient façonné d'inédit. Le livre de Carl Bode, The American Lyceum. Town Meeting of the Mind, qui portait sur les associations volontaires de type culturel ou littéraire, fut, à un double titre, une révélation : il constituait un modèle d'analyse d'un phénomène dont je soupçonnais la présence et l'importance au Québec et il me suggérait de chercher dans d'autres travaux historiques américains des phénomènes culturels marqués par la dimension coloniale des sociétés du Nouveau Monde. La culture des villes coloniales américaines devait être appréhendée autrement que celle des métropoles, que ce soit Paris, Londres, Madrid ou Lisbonne.

L'étude du phénomène des associations m'a mis sur la piste des archives inédites de l'Institut canadien de Montréal, sur celles du phénomène des conférences publiques, des débats, des bibliothèques. Bref, les formes culturelles, les objets possibles d'une histoire culturelle et intellectuelle d'une colonie britannique d'Amérique du Nord commençaient à se dessiner.

En tâtonnant, je finis par comprendre quand et comment allait se clore la culture de l'associationnisme. C'est après avoir fait l'histoire d'un lieu populaire de culture urbaine, le parc Sohmer (1899-1919) et compilé et analysé la statistique du cinéma que j'ai vu comment on passait dans le $\mathrm{XX}^{\mathrm{e}}$ siècle. Je fis le même exercice pour le libéralisme radical : comment survivait-il au déclin du libéralisme «rouge» et du discours de Laurier de 1877?

Je voyais bien la place prise par l'imprimé et la culture de l'imprimé parmi mes objets culturels : journaux, brochures, pamphlets, livres d'une part, phénomènes liés à la culture de l'imprimé (bibliothèques collectives et personnelles, librairie, «édition») d'autre part. Ce regard rétrospectif sur les sources de mes travaux indiquent deux choses : d'abord, les objets culturels que je retenais finalement étaient ceux d'individus instruits, éduqués, sachant parler, écrire, lire, polémiquer; j'excluais de fait la culture orale, celle des légendes, des contes, des proverbes, des chansons, et la culture matérielle, celle des artefacts de tout type. Ensuite, j'avais travaillé sur un lieu, l'agglomération, et sur un chantier, Montréal. L'imprimé, la bibliothèque de collectivité, les associations, l'édition, 
le parc d'amusement, la sociabilité étudiés étaient montréalais. Et toutes ces formes ou activités culturelles m'ont nécessairement confronté à la problématique de la culture urbaine?

Je privilégiais certes la trace imprimée ou manuscrite, celle de gens alphabétisés et de créateurs. Très tôt s'est posée la question de l'usage de la littérature dans mon corpus : allais-je inclure les romans, les poèmes, les pièces de théâtres, les essais? Comment ces sources allaientelles pouvoir être utilisées? Je ne voyais aucun problème pour les essais, genre hybride dans lequel on a tendance à mettre plus que moins d'œuvres; je découvrais même que les écrits de Parent, de Dessaulles ou de Buies, que les conférences publiques et les polémiques pouvaient permettre de renouveler la définition et la problématique de l'essai en posant justement la question du statut générique de toute cette prose d'idées du XIX ${ }^{e}$ siècle. Mais la fiction, toute réaliste qu'elle soit au XIX siècle québécois? Et la poésie, souvent circonstancielle? Faute d'y voir clair à ma satisfaction, je me limitai à utiliser le corpus poétique produit au temps du romantisme et des Rébellions ${ }^{10}$.

\section{Histoire culturelle, intellectuelle, des intellectuels}

En rencontrant les écrivains, les penseurs, les journalistes, les gens de lettres, la question s'est aussi posée de savoir ce qu'était un intellectuel et si cet intellectuel qui naît avec l'Affaire Dreyfus en France, avait une figure locale. Le corpus de textes utilisés et le bassin d'écrivains et de gens de lettres fréquentés m'ont fait affirmer que l'intellectuel comme on le définit dans les travaux français n'avait pas existé au Québec au XIXe siècle et qu'il apparait dans le lexique en 1901 et dans la réalité au début du $\mathrm{XX}^{\mathrm{ell}}$.

Ce parcours global m'a clairement fait voir que l'histoire socioculturelle englobe l'histoire intellectuelle qui englobe l'histoire des intellectuels. Si j'avais fait une histoire culturelle du Québec, je me serais intéressé à toutes les formes d'expression culturelle, imprimée, orale, matérielle, plastique. J'aurais moins constitué la trame des idées que fait voir l'apparition, l'évolution, l'hybridation et la disparition des formes et des institutions culturelles.

Je m'y suis intéressé, j'ai fait en partie cette histoire culturelle dans la mesure où on ne peut faire d'histoire intellectuelle sans faire l'histoire du contexte. D'où, pour moi, ce choix d'une histoire sociale des idées à propos de laquelle je m'explique de la façon suivante dans l'introduction à mon Histoire sociale des idées au Québec, I: 1760-1896"2: 
"Cette histoire est sociale en ce qu'elle entend rendre compte du circuit complet des idées, de leur production, de leur diffusion, de leur réception. Elle s'intéresse à l'appartenance sociale des individus qui formulent les idées (bourgeoisie francophone de professions libérales, clergé, bourgeoisie marchande anglophone, autorités coloniale et métropolitaine, citoyens), aux réseaux et aux médias qui diffusent les courants d'opinion et à la pénétration sociale des idées. Les chapitres II, $\mathrm{V}$, XIII et XV, en particulier, analysent la trame des institutions et des moyens culturels qui assurent la diffusion des idées, des débats et des polémiques.

Les idées de cette histoire sociale sont des idées civiques plus que strictement politiques, celles qu'on retrace dans le discours des hommes publics, civils et religieux. Ces idées civiques réfèrent aux grands courants de pensée et d'opinion qui ont traversé les deux siècles considérés : monarchisme, républicanisme, démocratie, Révolution et contre-Révolution, loyalisme, colonialisme, libéralisme, conservatisme, ultramontanisme, "nationalisme», "philosophisme», anticléricalisme, antisémitisme, communisme et anticommunisme, fascisme. Ce sont les trames de ces courants d'idées que nous suivons sur deux siècles. Même si référence est occasionnellement faite à la littérature, à la peinture et aux sciences, [nous] ne [prétendons] pas à une archéologie de la pensée québécoise à des périodes données, à l'identification d'une trame intellectuelle unique qui traverserait une époque donnée. Le projet n'est pas sans intérêt mais il n'était pas le [nôtre].

Cette histoire sociale des idées au Québec commence en 1760 et se terminera, dans un deuxième tome, en 1960. [Nous ne nions pas l'existence d'une trame intellectuelle en Nouvelle-France] - la forêt est là pour d'autres goûts, d'autres clairières - mais il est évident qu'en choisissant le début du régime colonial britannique [nous misions] sur l'avènement du régime parlementaire et de l'imprimé pour retracer l'émergence d'une opinion publique. Ce faisant, [nous privilégions] la culture bourgeoise, celle des individus instruits qui parlent, écrivent, laissent des traces dans de la correspondance, dans la presse ou dans des brochures. On ne trouvera donc pas ici une histoire de la culture populaire, rurale et urbaine, qui s'exprime dans le conte, la légende ou dans la culture matérielle, celle des objets, des costumes, de l'alimentation ou des motifs décoratifs. Il y a là [de possibles belles clairières] qui attendent la cognée...

Cette histoire sociale des idées au Québec, de la conquête et de la cession à la Révolution tranquille, est celle des francophones. On verra qu'il s'agit d'un choix pragmatique, car même si nous accordons beaucoup de place à la culture et aux institutions culturelles de la communauté anglophone, nous laissons à d'autres the taste for other clearings... 
L'histoire intellectuelle du Québec francophone sur deux siècles est aussi mise en rapport avec la situation internationale, en particulier avec ses anciennes mères patries et ses «métropoles» politico-culturelles : la France, l'Angleterre, les États-Unis et Rome. [Nous pensons] aussi que la présente histoire, tant par la comparaison des formes et institutions culturelles que par celle de leur contenu, pourra servir de modèle à d'autres histoires intellectuelles de régions du Canada sinon à une histoire intellectuelle du Canada même.» Clearings in the bushes...

\section{En guise de conclusion}

Si l'histoire des intellectuels fait partie de l'histoire intellectuelle, celle-ci s'insère dans une histoire culturelle, qui est sociale de part en part. C'est le caractère social de l'histoire culturelle qui oblige à un découpage de l'objet culturel, à une identification des objets sous considération. Ce choix épistémologique et méthodologique invite à tenir compte tout autant de l'analyse interne qu'externe des idées, des courants d'opinion, des débats. Pas de texte sans contexte, et en histoire intellectuelle, choix de passer par le texte, par la trace pour étudier le contexte.

En étudiant les idées philosophiques en circulation dans l'enseignement et dans la société québécoise de 1665 à 1920, j'ai essayé de comprendre pourquoi on avait adhéré à tel système d'idées (le sens commun, la philosophie chrétienne, le thomisme), pourquoi on avait rejeté tel autre (cartésianisme, Encyclopédie, kantisme) et pourquoi les quelques auteurs de philosophie (Demers, Pâquet, Lortie, Robert, Grenier) avaient écrit des œuvres marquées par ces mêmes choix ou comment un «dissident) scotiste comme le franciscain Ephrem Longpré avait été mal reçu et mal reconnu dans ce milieu.

Dans l'Histoire sociale des idées au Québec (1760-1896), je me suis intéressé à ce que j'ai appelé les idées civiques. Mon point de vue et mon choix furent ceux du citoyen, des idées et des débats qui concernent le citoyen. J'en prends pour indices la périodisation retenue, qui correspond à l'émergence de la démocratie parlementaire, et de la souveraineté du peuple, et la place faite à la tradition démocratique aux $\mathrm{XVIII}^{e}$ et $\mathrm{XIX}^{\mathrm{e}}$ siècles.

Ce choix permet de comprendre pourquoi l'histoire intellectuelle, telle que je la conçois et la pratique, accorde tout autant sinon plus d'importance à la marque du temps sur les idées qu'à la marque des idées sur le temps. 


\section{NOTES}

'Yvan Lamonde, «L'histoire culturelle comme domaine historiographique au Québec», Revue d'bistoire de l'Amérique frangaise, vol. 51, n 2 (automne 1997), pp. 285-299.

${ }^{2} Y v a n$ Lamonde, La notion de Lebenswelt chez Jobn Wild: introduction à la pensée de John Wild et à la phénoménologie aux États-Unis, avec un essai bibliographique des écrits de John Wild, Mémoire de M.A.(Philosophie), Université de Montréal, 1967, 81 p.

${ }^{3}$ Herbert W. Schneider, Histoire de la philosophie américaine, Paris, Gallimard, 1955, 460 p.

${ }^{4}$ Fernand Ouellet, Histoire économique et sociale du Québec 1760-1850, Montréal, Fides, 1966, 639 p.

${ }^{5}$ Voir les textes de Fernand Ouellet, Robert Mandrou, Serge Gagnon et Gérard Bouchard dans Histoire sociale/Social History (mai 1976), pp. 5-28; dix ans plus tôt, Alphonse Dupront avait contribué à un collectif issu d'un colloque à Laval, "Réflexions pour une histoire de la psychologie collective», dans C. Galarneau et E. Lavoie (dir.), France et Canada du XVT' au XX' siècle, Québec, PUL, 1966, pp. 189-207. "Voir mes réserves dans «La sociabilité et l'histoire socioculturelle : le cas de Montréal, 1760-1880,, dans Yvan Lamonde, Territoires de la culture québécoise, Sainte-Foy, PUL, 1991, pp. 71-74.

${ }^{7} Y v a n$ Lamonde, L'bistoire des idées au Québec, 1760-1960 : bibliographie des études, Montréal, Bibliothèque nationale du Québec, 1989, $167 \mathrm{p}$.

${ }^{8}$ Carl Bode, The American Lyceum. Town Meeting of the Mind, Carbondale, Southern Illinois University Press, 1968, 275 p.

'Yvan Lamonde, "Une problématique de culture urbaine», dans Yvan Lamonde, Territoires de la culture québécoise, Sainte-Foy, PUL, 1991, pp. 49-69.

${ }^{10}$ Sur l'état d'avancement de ma réflexion à propos des rapports entre histoire et littérature, entre «réalité» et fiction, voir Yvan Lamonde, "Quelle histoire nous contons-nous?h) dans les Cabiers des Dix de 2001 [à paraître].

"Yvan Lamonde, «Les "intellectuels" francophones au Québec au XIX" siècle : questions préalables", Revue d'bistoire de l'Amérique franfaise, vol. 48, $\mathrm{n}^{\circ} 2$ (automne 1994), pp. 153-185; «Les francs-tireurs. Les intellectuels au Québec (1900-1930)», dans M. Brunet et P. Lanthier (dir.), L'inscription sociale de l'intellectuel, Sainte-Foy, PUL, 2000, pp. 188-203; «La spécificité des intellectuels des années cinquante au Québec), 1997, Bulletin d'bistoire politique, vol. 3, n 1 (automne 1994), pp. 19-24; «Des intellectuels francophones en Amérique», dans M.-C. Granjon, N. Racine et M. Trebitsch (dir.), Histoire comparie des intellectuels, Paris, CNRS-Institut d'histoire du temps présent, pp. 179-183.

${ }^{12}$ Yvan Lamonde, Histoire sociale des idées au Québec, tome I, Ville Saint-Laurent, Fides, 2000, 572 p. 